\title{
How to Interpret Esophageal Impedance pH Monitoring
}

\author{
Yu Kyung Cho, MD \\ Department of Internal Medicine, The Catholic University of Korea, School of Medicine, Seoul, Korea
}

\begin{abstract}
Esophageal impedance $\mathrm{pH}$ monitoring provides quantitative data on esophageal acid exposure and has the ability to correlate the symptoms with acid exposure events. The nomenclature for the reflux patterns detected in impedance $\mathrm{pH}$ monitoring as well as the normal values have been determined. Data interpretation is similar to 24-hour pH monitoring, ie, searching for an increase in the number of reflux episodes, prolonged acid or volume exposure or increased numbers of proximal reflux events. In particular, the key clinical measurements for impedance testing on proton pump inhibitor therapy are the number of acid and non-acid reflux episodes and their relationship with the symptoms using the symptom index or symptom-association probability.
\end{abstract}

(J Neurogastroenterol Motil 2010;16:327-330)

Key Words

Gastroesophageal reflux, Electric impedance, Reference values

\section{Introduction}

Esophageal impedance monitoring is considered the most sensitive tool for assessing all types of gastroesophageal reflux (acidic, weakly acidic and weakly alkaline), their composition, proximal extent, duration and clearing. Proper and coherent interpretation is needed to apply the results of impedance $\mathrm{pH}$ monitoring.

\section{What Is Impedance?}

Impedance techniques are based on measurements of the electrical impedance between closely arranged electrodes mount- ed on a thin intraluminal probe. Pairs of electrodes representing an impedance segment are connected to an impedance voltage transducer, which delivers a measuring current. The output of the measurement represents the electrical impedance around the catheter in the section between the pair of electrodes. The impedance is inversely proportional to the electrical conductivity of the luminal contents and the cross-sectional area between the 2 electrodes. Air has low conductivity and causes an increase in impedance, whereas swallowed or refluxed material has a high conductivity and causes a decrease in impedance.

The changes in the temporal-spatial patterns in impedance have been identified at various levels within the esophagus, allowing differentiation between antegrade (ie, swallow) and retrograde (ie, reflux) bolus movement. In this manner, the im-

Received: June 9, 2010 Revised: June 27, 2010 Accepted: June 28, 2010

(c) This is an Open Access article distributed under the terms of the Creative Commons Attribution Non-Commercial License (http://creativecommons. org/licenses/by-nc/3.0) which permits unrestricted non-commercial use, distribution, and reproduction in any medium, provided the original work is properly cited.

*Correspondence: Yu Kyung Cho, MD

Department of Internal Medicine, Seoul St. Mary's hospital, The Catholic University of Korea, School of Medicine, 505

Bandpo-dong, Seocho-gu, Seoul 137-049, Korea

Tel: +82-2-2258-6024, Fax: +82-2-2258-2053, E-mail: ykcho@catholic.ac.kr

Financial support: None.

Conflicts of interest: None. 


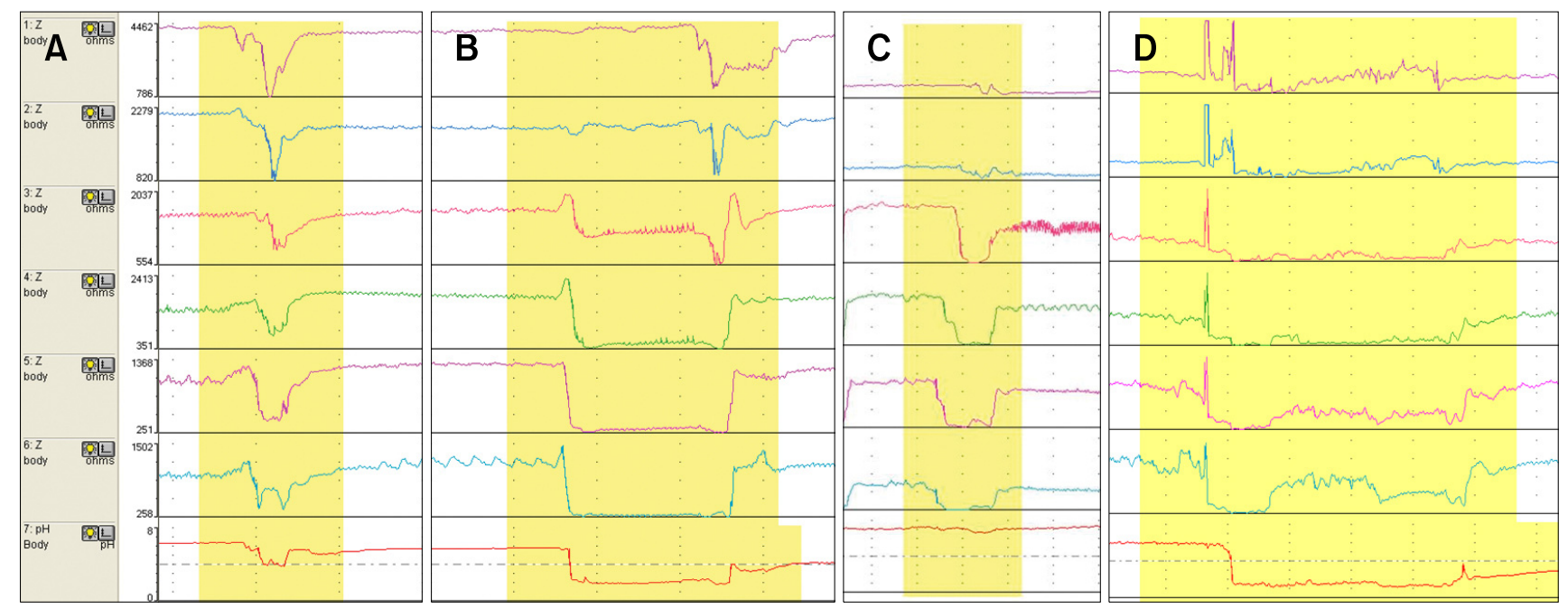

Figure 1. Esophageal impedance $\mathrm{pH}$ recordings showing examples of the 4 types of reflux. (A) Weakly acidic reflux, (B) acid reflux, (C) weakly alkaline reflux and (D) superimposed acid reflux.

pedance can be used to evaluate the intraesophageal liquid movements (bolus transit tests and reflux monitoring) or gas movement (aerophagia and belching).

\section{Reflux, Terminology of Impedance pH -}

A recent consensus report provided a detailed nomenclature for the reflux patterns detected by impedance-pH monitoring. ${ }^{1}$ Reflux is defined as either pure liquid or a mixture of liquid and gas detected by impedance. Liquid only reflux is defined as a retrograde $50 \%$ decrease in impedance from the baseline in the 2 distal impedance sites. Gas reflux was defined as a simultaneous increase in impedance $>3,000 \Omega$ in any 2 consecutive impedance sites with 1 site having an absolute value $>7,000 \Omega$. Mixed liquid gas reflux is defined as gas reflux occurring during or immediately before liquid reflux.

The 4 subcategories of reflux are based on the esophageal $\mathrm{pH}$ detected by impedance during reflux (Fig. 1): (1) acid reflux, a decrease in $\mathrm{pH}$ to $<4$; (2) superimposed acid reflux (acid re-reflux), reflux while the $\mathrm{pH}$ is $<4$ during an acid clearing interval (before the esophageal $\mathrm{pH}$ has recovered to $>4$ after acid reflux); (3) weakly acid reflux, the $\mathrm{pH}$ nadir is $>4$ but $<7$ during reflux and (4) weakly alkaline reflux, $\mathrm{pH}$ remains $>7$ or increases to $>7$. $\mathrm{pH}$-only reflux is defined as a decrease in $\mathrm{pH}$ to $<4$ in the absence of reflux detected by impedance monitoring ${ }^{2,3}$ and is quite rare.

Acid exposure (\%) is defined as the total time the $\mathrm{pH}$ is $<4$ divided by the time monitored. Bolus exposure (\%) is defined as

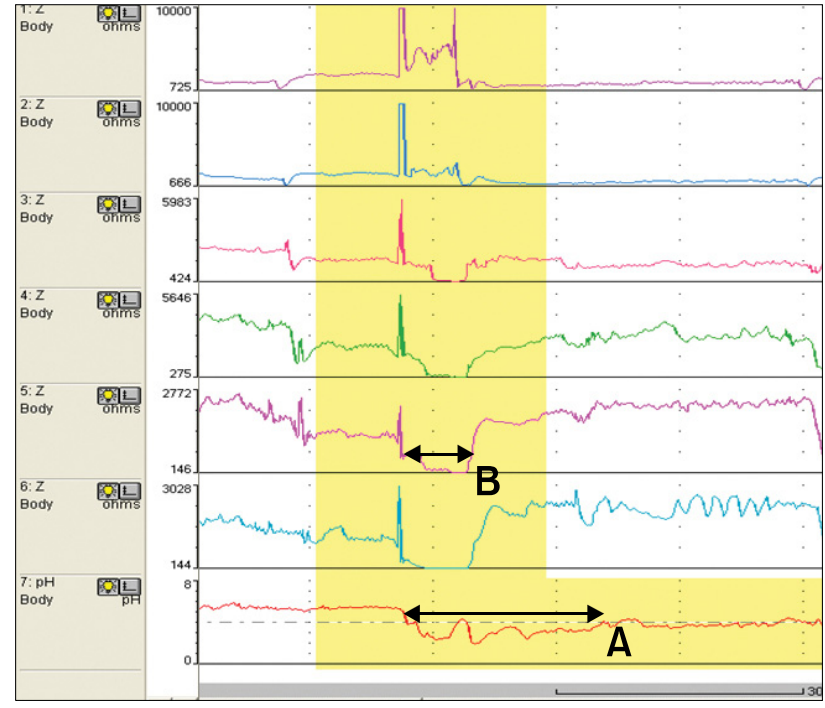

Figure 2. Example of acid reflux. (A) Acid duration measured 5 $\mathrm{cm}$ above the lower esophageal sphincter. (B) Bolus duration measured $5 \mathrm{~cm}$ above the lower esophageal sphincter.

being analogous to acid exposure by adding the duration of all four reflux subcategories defined by the impedance, and dividing this value by the time monitored. A healthy volunteer study performed by Shay et $\mathrm{al}^{4}$ revealed the median total acid exposure measured by $\mathrm{pH}$ to be 2.4 times higher than that of the total bolus exposure measured by impedance.

The acid duration is defined as the time after acid reflux or a $\mathrm{pH}$ only reflux until $\mathrm{pH} 4$ is again achieved for 5 or more 
seconds. The bolus duration is the time from liquid bolus entry to liquid bolus clearance, which is defined as the time when the impedance increases to a value denoting liquid reflux entry for $>5$ seconds. The bolus duration is measured at the impedance site 5 $\mathrm{cm}$ above the lower esophageal sphincter. The bolus duration and acid duration could be compared most accurately by examining the individual episodes of acid reflux that have no superimposed acid reflux (Fig. 2).

\section{Normal Values}

If the primary aim of the study is to confirm an unclear diagnosis of gastroesophageal reflux disease, refractory patients with troubling gastroesophageal reflux disease complaints or extraesophageal symptoms or before antireflux surgery should undergo $\mathrm{pH}$ testing off medications, and the results would be interpreted based on the traditional acid parameters. For those with well-defined GERD and troubling symptoms that persist on treatment, impedance-pH testing while on therapy would be indicated. ${ }^{5}$ In this setting, impedance $\mathrm{pH}$ monitoring can help assess the efficacy of proton pump inhibitors (PPIs) and the role of nonacid or acid reflux in persistent symptoms.

Normal values for impedance-pH monitoring off acid-suppression therapy have been determined from US and European studies (Table 1). ${ }^{4,6}$ In healthy adults, the total number of reflux episodes measured by impedance-pH was approximately 40 over a 24-hour period. Acid reflux was 2 times more common than weakly acid reflux. Superimposed acid reflux and weakly alkaline reflux were rare. A median of $34 \%$ of the upright reflux reached the proximal esophagus. Based on the 95th percentile as the upper limit of normal, they proposed normal total distal reflux to be total reflux events $\leq 73$, acid reflux events $\leq 55$, weakly acid reflux events $\leq 26$ and weakly alkaline reflux $\leq 1$.

Acid neutralization to $\mathrm{pH} 4$ takes twice as long as the volume clearance measured by impedance (Table 2). This suggests that although impedance monitoring can determine the clearing of most acid boluses, the $\mathrm{pH}$ probe detects even small acid resides. ${ }^{4,6}$ Non-acidic reflux (although most is actually weak acid) commonly occurs postprandially when the gastric content is buffered after a meal or during acid suppression with PPIs. ${ }^{7}$

The on-therapy normal values are needed because esophageal impedance $\mathrm{pH}$ monitoring is most likely to be used for symptomatic patients on acid-suppression therapy. Vela et $\mathrm{al}^{8}$ reported that PPI therapy reduced the number of acid reflux episodes with a proportional increase in nonacid reflux, the net result of which was an unchanged total number of reflux episodes on or off therapy as observed during post-prandial studies. The normal range of reflux episodes "on therapy" (<73) has been determined by extrapolating the data from healthy volunteers "off therapy" ${ }^{4}$ and by assuming that PPI primarily changes the $\mathrm{pH}$ of the refluxate without affecting the total number of reflux episodes. ${ }^{8}$ However, Tutuian et $\mathrm{al}^{9}$ reported that PPI therapy reduces the number of acid reflux episodes but not the number of non-acid reflux episodes, indicating that the upper limit of normal for patients on twice daily PPI therapy should be 48 reflux events.

\section{Analysis of Impedance pH Data}

Evaluation of the data derived from esophageal impedance $\mathrm{pH}$ monitoring can be subdivided into analysis of

- the $\mathrm{pH}$ data alone,

Table 2. Normal Values for Impedance $\mathrm{pH}$ monitoring; Bolus Exposure and Acid Exposure (95th percentile) ${ }^{4}$

\begin{tabular}{lcc}
\hline & $\begin{array}{c}\text { \% bolus exposure } \\
\text { (Impedance parameter) }\end{array}$ & $\begin{array}{c}\% \text { acid exposure } \\
(\mathrm{pH} \text { parameter })\end{array}$ \\
\hline Total & 1.4 & 6.3 \\
Upright & 2.1 & 9.7 \\
Recumbent & 0.7 & 2.1 \\
\hline
\end{tabular}

Table 1. Normal Values for Impedance pH Monitoring; Reflux Episodes (95th percentile) ${ }^{4}$

\begin{tabular}{|c|c|c|c|c|c|c|c|c|c|c|}
\hline & \multicolumn{5}{|c|}{ Distal reflux events ( $5 \mathrm{~cm}$ above LES) } & \multicolumn{5}{|c|}{ Proximal reflux events (15 cm above LES) } \\
\hline & Total & Acid & $\begin{array}{c}\text { Weakly } \\
\text { acid }\end{array}$ & $\begin{array}{l}\text { Weakly } \\
\text { alkaline }\end{array}$ & $\begin{array}{l}\text { Super- } \\
\text { imposed } \\
\text { acid }\end{array}$ & Total & Acid & $\begin{array}{c}\text { Weakly } \\
\text { acid }\end{array}$ & $\begin{array}{l}\text { Weakly } \\
\text { alkaline }\end{array}$ & $\begin{array}{c}\text { Super- } \\
\text { imposed } \\
\text { acid }\end{array}$ \\
\hline Total & 73 & 55 & 26 & 1 & 4 & 31 & 28 & 12 & 1 & 2 \\
\hline Upright & 67 & 52 & 24 & 1 & 4 & 29 & 25 & 11 & 1 & 2 \\
\hline Recumbent & 7 & 5 & 4 & 0 & 1 & 3 & 2 & 1 & 0 & 0 \\
\hline
\end{tabular}

LES, lower esophageal sphincter. 
- the impedance (bolus transit) data alone,

- the temporal relationship between $\mathrm{pH}$ change and impedance change,

- the temporal relationship between reflux episodes and the occurrence of symptoms

First, impedance-pH monitoring should be analyzed in a quantitative manner, similar to 24-hour $\mathrm{pH}$ monitoring, by searching for an increased numbers of reflux episodes, prolonged acid or volume exposure or increased numbers of proximal reflux events. Impedance testing can detect the ingestion of acidic beverages that is characterized by antegrade acidic impedance movement, which may be misinterpreted by traditional $\mathrm{pH}$ testing.

The key clinical measurement for impedance testing is the number of acid and non-acid reflux episodes as well as their relationship with the symptoms. In patients on PPI, qualitative analysis of the reflux-symptom association using symptom index or symptom association probability is essential.

\section{Conclusion}

Esophageal impedance $\mathrm{pH}$ monitoring provides quantitative data on the level of esophageal acid exposure and on the temporal correlation between the patient's symptoms and reflux events. Normal impedance $\mathrm{pH}$ values for off PPI therapy have been suggested. In patients on PPI therapy, the primary measurement is the number of acid and non-acid reflux episodes as well as their relationship with the symptoms.

\section{References}

1. Sifrim D, Castell D, Dent J, Kahrilas PJ. Gastro-oesophageal reflux monitoring: review and consensus report on detection and definitions of acid, non-acid, and gas reflux. Gut 2004;53:1024-1031.

2. Zerbib F, Roman S, Ropert A, et al. Esophageal pH-impedance monitoring and symptom analysis in GERD: a study in patients off and on therapy. Am J Gastroenterol 2006;101:1956-1963.

3. Agrawal A, Tutuian R, Hila A, Freeman J, Castell DO. Ingestion of acidic foods mimics gastroesophageal reflux during $\mathrm{pH}$ monitoring. Dig Dis Sci 2005;50:1916-1920.

4. Shay S, Tutuian R, Sifrim D, et al. Twenty-four hour ambulatory simultaneous impedance and $\mathrm{pH}$ monitoring: a multicenter report of normal values from 60 healthy volunteers. Am J Gastroenterol 2004; 99:1037-1043.

5. Hirano I, Richter JE. Practice parameters committee of the American College of Gastroenterology. ACG practice guidelines: esophageal reflux testing. Am J Gastroenterol 2007;102:668-685.

6. Zentilin P, Iiritano E, Dulbecco P, et al. Normal values of 24-h ambulatory intraluminal impedance combined with $\mathrm{pH}$-metry in subjects eating a Mediterranean diet. Dig Liver Dis 2006;38:226-232.

7. Sifrim D, Holloway R, Silny J, Tack J, Lerut A, Janssens J. Composition of the postprandial refluxate in patients with gastroesophageal reflux disease. Am J Gastroenterol 2001;96:647-655.

8. Vela MF, Camacho-Lobato L, Srinivasan R, Tutuian R, Katz PO, Castell DO. Simultaneous intraesophageal impedance and $\mathrm{pH}$ measurement of acid and nonacid gastroesophageal reflux: effect of omeprazole. Gastroenterology 2001;120:1599-1606.

9. Tutuian R, Mainie I, Agrawal A, Freeman J, Castell DO. Normal values for ambulatory 24-hour combined impedance-pH monitoring on acid suppressive therapy. Gastroenterology 2006;130(suppl 2): A171. 